\title{
Results of a Phase I Trial of Induction Cisplatin, Docetaxel, 5-FU and Erlotinib Followed by Cisplatin, Bevacizumab and Erlotinib with Radiotherapy for Advanced Head and Neck Cancer
}

P. H. Ahn

Thomas Jefferson University and Hospitals

M. Machtay

University Hospitals Case Western Reserve University

P. R. Anné

Thomas Jefferson University and Hospitals

E. Wuthrick

Thomas Jefferson University and Hospitals. Follow this and additional works at: https://jdc.jefferson.edu/bodinejournal

Marteante Oncology Commons

Themas Jefferson University and Hospitals to this document benefits you

\section{Seenextpaga far additional authors}

Ahn, P. H.; Machtay, M.; Anné, P. R.; Wuthrick, E.; Keane, W. M.; Cognetti, D.; Dicker, A. P.; and Axelrod, R. S. (2010) "Results of a Phase I Trial of Induction Cisplatin, Docetaxel, 5-FU and Erlotinib Followed by Cisplatin, Bevacizumab and Erlotinib with Radiotherapy for Advanced Head and Neck Cancer," Bodine Journal: Vol. 3 : Iss. 1 , Article 22.

DOI: https://doi.org/10.29046/TBJ.003.1.021

Available at: https://jdc.jefferson.edu/bodinejournal/vol3/iss1/22

This Article is brought to you for free and open access by the Jefferson Digital Commons. The Jefferson Digital Commons is a service of Thomas Jefferson University's Center for Teaching and Learning (CTL). The Commons is a showcase for Jefferson books and journals, peer-reviewed scholarly publications, unique historical collections from the University archives, and teaching tools. The Jefferson Digital Commons allows researchers and interested readers anywhere in the world to learn about and keep up to date with Jefferson scholarship. This article has been accepted for inclusion in Bodine Journal by an authorized administrator of the Jefferson Digital Commons. For more information, please contact: JeffersonDigitalCommons@jefferson.edu. 
Results of a Phase I Trial of Induction Cisplatin, Docetaxel, 5-FU and Erlotinib Followed by Cisplatin, Bevacizumab and Erlotinib with Radiotherapy for Advanced Head and Neck Cancer

Authors

P. H. Ahn, M. Machtay, P. R. Anné, E. Wuthrick, W. M. Keane, D. Cognetti, A. P. Dicker, and R. S. Axelrod 


\title{
Results of a Phase I Trial of Induction Cisplatin, Docetaxel, 5-FU and Erlotinib Followed by Cisplatin, Bevacizumab and Erlotinib with Radiotherapy for Advanced Head and Neck Cancer
}

\author{
Ahn, P.H., ${ }^{1}$ Machtay, M., ${ }^{2}$ Anné, P.R., ${ }^{1}$ Wuthrick, E., ${ }^{1}$ Keane, W.M., ${ }^{3}$ Cognetti, D., ${ }^{3}$ Dicker, A.P., ${ }^{1}$ Axelrod, R.S. ${ }^{4}$ \\ ${ }^{1}$ Department of Radiation Oncology, Thomas Jefferson University and Hospitals, Philadelphia, PA \\ 'University Hospitals Case Western Reserve University, Cleveland, $\mathrm{OH}$ \\ ${ }^{3}$ Department of Otolaryngology, Thomas Jefferson University and Hospitals, Philadelphia, PA \\ ${ }^{4}$ Department of Medical Oncology, Thomas Jefferson University and Hospitals, Philadelphia, PA
}

\section{Background}

A phase I trial of induction cisplatin, docetaxel, 5-FU and erlotinib (TPF-E) followed by cisplatin, bevacizumab and erlotinib (PA-E) with radiotherapy (XRT) for advanced head and neck cancer (HNC) was conducted.

\section{Methods}

Eligible patients had stage IVA-C HNC, with performance status (PS) 0 or 1, good hematologic and renal reserve, and no pre-existing grade 2 cardiovascular comorbidities. Two cycles of induction q3 week TPF-E were administered, with $75 \mathrm{mg} / \mathrm{m}^{2}$ cisplatin, $75 \mathrm{mg} / \mathrm{m}^{2}$ docetaxel, and $750 \mathrm{mg} / \mathrm{m}^{2}$ days 1-4 CI 5-FU during each cycle. Initial dose of erlotinib was $50 \mathrm{mg}$ daily from start of induction chemotherapy until radiotherapy completion. Dose escalation levels of erlotinib with $100 \mathrm{mg}$ and $150 \mathrm{mg}$ were performed. XRT was administered with concurrent cisplatin $30 \mathrm{mg} / \mathrm{m}^{2}$ weekly and bevacizumab $10 \mathrm{mg} /$ kg q2 weeks. Dose limiting toxicity (DLTs) were defined as Grade 4-5 toxicity or Grade 3 toxicity attributable to erlotinib and requiring hospitalization. This trial was supported by a grant from Genentech.

\section{Results}

13 patients with previously untreated local-regionally advanced (11 patients) or previously untreated locoregional disease with oligometastatic disease (two patients) HNC were enrolled. Two patients in cohort 1 (erlotinib 50mg) did not complete XRT due to noncompliance or progression. One patient received induction Avastin with TPF-E and developed GI perforation, prompting deletion of Avastin from induction TPF-E. Four of five evaluable patients in cohort 1 completed both TPF-E and XRT with PA-E (erlotinib 50mg; erlotinib discontinued due to intractable diarrhea). Three of four patients in cohort 2 completed all therapy (100mg; patient with DLT of colonic perforation in diverticulum during induction TPF-E). Zero of one patient in cohort 3 completed all therapy (150mg; diarrhea, abscess and decreased PS). There were no Grade 5 toxicities; one patient in cohort 1 died soon after treatment with no cause on autopsy. One patient in the final regimen had significant gastrointestinal complications (perforation). At median 13.2 month follow-up, 7 patients (54\%) are alive with no evidence of disease, and 2 (15\%) are alive with recurrent but stable disease.

\section{Conclusion}

Erlotinib in combination with induction TPF followed by erlotinib with XRT, cisplatin and bevacizumab is active but toxic. MTD was reached at $100 \mathrm{mg}$ erlotinib, but overall rates of treatment compliance were low, in part due to gastrointestinal toxicities and poor PS after induction therapy. Gastrointestinal toxicity proved to be the most frequent reason for morbidity and DLT in this study.

This trial was supported by a grant from Genentech. 